Especial: Profesores de Estudios Generales Investigan

II Sección: Docentes e investigación: tarea continua en Estudios Generales

\title{
Pensamientos filosóficos de la independencia: Louverture, Bolívar y Morazán
}

\author{
Gabriela Rangel Díaz \\ Universidad Teológica de América Central (UTAC), Costa Rica \\ gabrielarangel02@gmail.com \\ https://orcid.org/0000-0002-1635-5864
}

Recibido: 31 de noviembre de 2019

Aceptado: 31 de enero de 2020

Resumen: Esta investigación pone de relieve las ideas y luchas llevadas a cabo por tres independentistas de América Latina: Toussaint Louverture, de Haití; Simón Bolívar, de Venezuela, y Francisco Morazán, de Honduras. Los tres, desde diferentes flancos de acción y contextos, compartieron pensamientos filosóficos similares en torno a la independencia y lo que esta pudiera implicar para los pueblos latinoamericanos sedientos de libertad, pero analfabetos en su administración.

Diversos eventos históricos exhortaron pensamientos independentistas en América Latina; sin embargo, los dos más destacables fueron: La Revolución francesa y la Declaración de los Derechos del Hombre y del Ciudadano. No obstante, se concluye que la independencia no es un hecho, sino un proceso inacabado.

Palabras clave: independencia; libertad; Francisco Morazán; Toussaint Louverture; Simón Bolívar.

\section{Philosophical thoughts of independence: Louverture, Bolívar y Morazán}

\section{(๑) $\Theta \odot$}

La Revista Estudios es editada por la Universidad de Costa Rica y se distribuye bajo una Licencia Creative Commons Atribución-NoComercial-CompartirIgual 3.0 Costa Rica. Para más información envíe un mensaje a 


\section{Especial: Profesores de Estudios Generales Investigan}

Abstract: This research highlights the ideas and struggles carried out by three Latin American independence fighters: Toussaint Louverture, from Haiti; Simón Bolívar, from Venezuela, and Francisco Morazán, from Honduras. The three of them, from different sides of action and contexts, shared similar philosophical thoughts about independence and what it might mean for Latin American peoples who are thirsty for freedom but illiterate in their administration.

Several historical events have called for independence thinking in Latin America, however, the two most notable were: the French Revolution and the Declaration of the Rights of Man and the Citizen. Nevertheless, it is concluded that independence is not a fact, but an unfinished process.

Keywords: Independence; liberty; Francisco Morazán; Toussaint Louverture; Simón Bolívar.

\section{Introducción}

La independencia de América Latina, más que un hecho, es un proceso. La independencia también era un sueño para los independentistas. Fueron muchas las personas que se prepararon políticamente, que investigaron, que tuvieron largas discusiones a la luz del candil y de la esperma, con amaneceres llenos de dudas y preguntas, cuestionándose finalmente cuál sería la mejor forma política para el Estado que ellos deseaban para América Latina, para sus territorios, para sus regiones.

Una de las mayores dudas que asaltaba a los pueblos latinoamericanos era ¿qué significaba ser independientes? ¿Qué responsabilidades implicaba esa independencia? ¿Podrían sobrevivir sin la guía de Europa? Cuando los pueblos han conocido por siglos la dominación, la dependencia, la sumisión, el dolor, la inferioridad, empoderarse y ser independientes es algo verdaderamente temeroso.

Bolívar, Martí, Toussaint Louverture e inclusive Morazán lo sabían, y aun así dieron pasos de gigante en medio de pueblos que no estaban ni mental, ni emocional, ni políticamente preparados. Pensar la independencia era un gran

\section{(c) (i) (-)}

La Revista Estudios es editada por la Universidad de Costa Rica y se distribuye bajo una Licencia Creative Commons Atribución-NoComercial-CompartirIgual 3.0 Costa Rica. Para más información envíe un mensaje a 


\section{Especial: Profesores de Estudios Generales Investigan}

esfuerzo intelectual, preguntarse por otros países de Europa que eran independientes era preguntarse también por el futuro, por un más allá que se deseaba, que se esperaba, pero que no se sabía cómo materializar.

La independencia, más que un proceso doloroso, largo y tedioso, fue un proceso desgastante intelectualmente, agotador, pero a su vez revelador de lo que tienen los pueblos para dar, para desarrollar y de lo que tienen, pero se niegan a cambiar.

La independencia al presente nos puede parecer natural, asumida, pero la pregunta real es si la hemos consumado, o si sigue estando -para la mayor tristeza de Bolívar y los otros independentistas- en el papel, en la mentalidad del americano, pero no en la realidad ni en su vivencia cotidiana.

\section{Contexto de la independencia entre dos mundos}

Desde el ambiente político, económico y social de la Europa del siglo XIX, brindarle la independencia a América Latina era una idea aberrante, impensable e inclusive un tema que no ameritaba ninguna atención en la Corte Real.

Cuando España ingresó por primera vez al territorio americano conquistó y colonizó con una serie de dispositivos de poder político-religiosos y económicos nunca antes vistos. Algunos de ellos se pueden identificar en la Bula Inter Caetera (2010), un documento oficial emitido por el Papa Alejandro VI, el cual, como representante de Dios en la tierra, tenía amplias potestades para respaldar a la Corona española en todas y cada una de las decisiones que tomara sobre los habitantes del Nuevo Mundo y sus territorios.

\section{(c) (i) (2)}

La Revista Estudios es editada por la Universidad de Costa Rica y se distribuye bajo una Licencia Creative Commons Atribución-NoComercial-CompartirIgual 3.0 Costa Rica. Para más información envíe un mensaje a 
ISSN 1659-3316

\section{Especial: Profesores de Estudios Generales Investigan}

Entre las consideraciones que se abroga este texto y otros de la época escritos por frailes religiosos como Fray Victoria, se encuentran aquellas de carácter religioso: como que los indios no tienen alma, no son humanos, sino salvajes y, por tanto, los españoles los van a civilizar y evangelizar para que olviden sus dioses paganos y se conviertan al cristianismo.

Entre las obras agradables a la divina Majestad y deseables para nuestro corazón existe ciertamente aquella importantísima, a saber, que, principalmente en nuestro tiempo, la fe católica y la religión cristiana sean exaltadas y que se amplíen y dilaten por todas partes y que se procure la salvación de las almas y que las naciones bárbaras sean abatidas y reducidas a dicha fe. (p.1)

En lo político, Alejandro VI brinda total derecho de ocupación sobre las tierras descubiertas y por descubrir en América, así como la demanda de obediencia a los pobladores.

... como Vicario de Jesucristo, a tenor de las presentes, os donamos, concedemos y asignamos perpetuamente, a vosotros y a vuestros herederos y sucesores en los reinos de Castilla y León, todas y cada una de las islas y tierras predichas y desconocidas que hasta el momento han sido halladas por vuestros enviados y las que se encontrasen en el futuro y que en la actualidad no se encuentren bajo el dominio de ningún otro señor cristiano, junto con todos sus dominios, ciudades, fortalezas, lugares y villas, con todos sus derechos, jurisdicciones correspondientes y con todas sus pertenencias; y a vosotros y a vuestros herederos y sucesores os investimos con ellas y os hacemos, constituimos y deputamos señores de las mismas con plena, libre y omnímoda potestad, autoridad y jurisdicción. (p.2)

En lo referente al ámbito social, no solo determinan quiénes son humanos y quiénes no, quiénes ciudadanos y quiénes no, sino también establecen categorizaciones de los pobladores de América a partir del color de la piel e inclusive generan un sistema de castas racista identificado por los historiadores 


\section{Especial: Profesores de Estudios Generales Investigan}

Ángel Rosenblat y Gonzalo Aguirre Beltrán, de Argentina y México, respetivamente. Existen también otros dispositivos culturales que se impregnan a través de la imposición del lenguaje y de las costumbres.

Sin embargo, todos los anteriores empiezan a ser cuestionados con las luchas en pro de la abolición de la esclavitud que se empiezan a gestar desde diferentes latitudes del globo. Ya en vida, Bartolomé de las Casas cuestionaba el trato que se les brindaba a los indígenas; se preguntaba, además, que, si eran criaturas de Dios, por qué entonces no eran libres.

Los reclamos de este fraile dominico incomodaron, pero no fueron grandemente atendidos. No obstante, con el pasar de los tiempos tuvieron eco en otras latitudes, como Francia e Inglaterra, quienes también, desde distintos contextos y problemas, empiezan a enfrentarse a cuestionamientos sobre su función colonizadora en la historia, lo anterior por parte de las nuevas clases sociales que ascendían en poder económico y cada vez más instruidas, como la burguesa.

Aunado a lo anterior, en 1789 sucede un giro copernicano en la historia política del mundo: la Revolución francesa, un evento en el cual cae la monarquía y se da una ruptura con la Iglesia católica, encaminándose hacia la construcción de un Estado laico, que ya venía poniendo en tela de juicio el actuar de la Iglesia en muchos sentidos.

Además, empieza a surgir la preocupación por los derechos humanos y los del francés con la Declaración de los Derechos del Hombre y del Ciudadano.

Surge el enciclopedismo como movimiento filosófico coordinado por D’Alambert y Diderot, así también la primera imprenta con Gutenberg, entre otras invenciones que facilitaron el acceso al conocimiento entre el vulgo, antes solo reservado a la Iglesia. Los descubrimientos científicos de Galileo se empiezan a

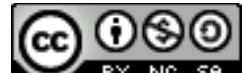

La Revista Estudios es editada por la Universidad de Costa Rica y se distribuye bajo una Licencia Creative Commons Atribución-NoComercial-CompartirIgual 3.0 Costa Rica. Para más información envíe un mensaje a revistaestudios.eeg@ucr.ac.cr. 


\section{Especial: Profesores de Estudios Generales Investigan}

conocer, pero la Iglesia lo calla. Ese continuo estira y encoge entre la Iglesia, sus prohibiciones y represiones en lo que respecta a política, ciencia y otros ámbitos empiezan a generar una fractura cada vez más evidente en Europa.

Aun así, la Iglesia católica seguía teniendo un gran dominio en América Latina; pese a eso no se puede omitir que también estaban latentes las insurrecciones de grupos de esclavos cansados de los maltratos, abusos y explotación, como sucedió en Haití, Argentina y México, zonas con gran producción de caña de azúcar, oro y otros minerales. Empero, todas las rebeliones solían ser siempre reprimidas más por la fuerza militar de los colonos que por la fuerza religiosa. Hasta los originarios empiezan a perderle el miedo a la religión y a tomar más conciencia de la anulación de sus raíces espirituales, los votos de obediencia que el catolicismo demandaba desde la Bula Inter Caetera ya no convenían a las multitudes inconformes.

Así también, criollos de generaciones muy posteriores al 1700 empiezan a dar la libertad a sus esclavos, otros la compran con su trabajo, y algunos hijos de europeos o americanos más versados en lo que sucedía en Europa decían no verle sentido a las estructuras coloniales, a la esclavitud, y consideraban que América Latina debía regirse por sí sola; por ende, ya era hora de luchar por su independencia, así como Francia luchó por su libertad.

\section{Toussaint Louverture y la primera revolución esclava}

Toussaint Breda es su nombre de pila debido a que nació en la hacienda del conde de Breda, posteriormente será conocido como Toussaint Louverture. Haitiano de origen esclavo y liberto a los 33 años es poco mencionado entre los

\section{(C) $(000$}

La Revista Estudios es editada por la Universidad de Costa Rica y se distribuye bajo una Licencia Creative Commons Atribución-NoComercial-CompartirIgual 3.0 Costa Rica. Para más información envíe un mensaje a 


\section{Especial: Profesores de Estudios Generales Investigan}

independentistas de América Latina, a pesar de que su país fue el primero en lograr la tan ansiada libertad política en 1804.

Era un hombre con una gran viveza e inteligencia, desde muy joven su dueño le permitió aprender a leer y a escribir en francés, lenguaje de los conquistadores, a pesar de que la lengua más hablada entre los esclavos era el créole. Fue cochero, terrateniente de la hacienda Breda e inclusive llegó a recibir entrenamiento militar de los españoles antes de enfrentarlos y proclamarse primer gobernador negro de la Isla Santo Domingo.

Aunque Haití es hoy en día el país más pobre de América Latina, no siempre fue así; en los inicios del periodo colonial fue uno de los mayores proveedores de ciertas materias primas en extremo raras, valiosas e importantes para los europeos de la alta sociedad: el azúcar, el tabaco y el café, gracias a la explotación de amplias plantaciones, sin olvidar el oro que extraían de las minas.

Desde 1492 fue uno de los primeros territorios colonizados por los españoles con la llegada de Cristóbal Colón a América. Haití fue nombrada por Colón como La Española. En 1605 el gobernador Antonio de Osorio exige despoblar las zonas oeste y centrales de la isla para combatir el comercio informal de los colonos criollos. Sin embargo, al quedar estas zonas despobladas, fueron cuna de bucaneros y filibusteros de origen francés que poco a poco se fueron asentando. Debido a lo anterior, en 1697 Francia reclama estos territorios y España los cede mediante el Tratado de Ryswick, fundándose así la colonia francesa de Saint Domingue. Francia va poco a poco desplazando a España en poder económico, cantidad de esclavos y con formas cada vez más crueles de explotación.

Debido a lo anterior, en 1790 hay un primer intento de rebelión, en el cual por primera vez se unen terratenientes, esclavos, comerciantes y blancos de bajo 


\section{Especial: Profesores de Estudios Generales Investigan}

nivel económico. Este primer intento de libertad no fructificó, fue aplacado por los blancos dueños de las plantaciones. Sin embargo, lo más interesante es que se reunieron personas provenientes de diferentes estratos sociales, pero con un solo interés: administrar el territorio ellos mismos y no seguir alimentando la gula de riquezas de los conquistadores.

Cabe preguntarse entonces ¿cómo consigue Haití ser el primer pueblo independiente frente a tal situación de dominación? Lo anterior se puede explicar mejor mediante la siguiente línea del tiempo:
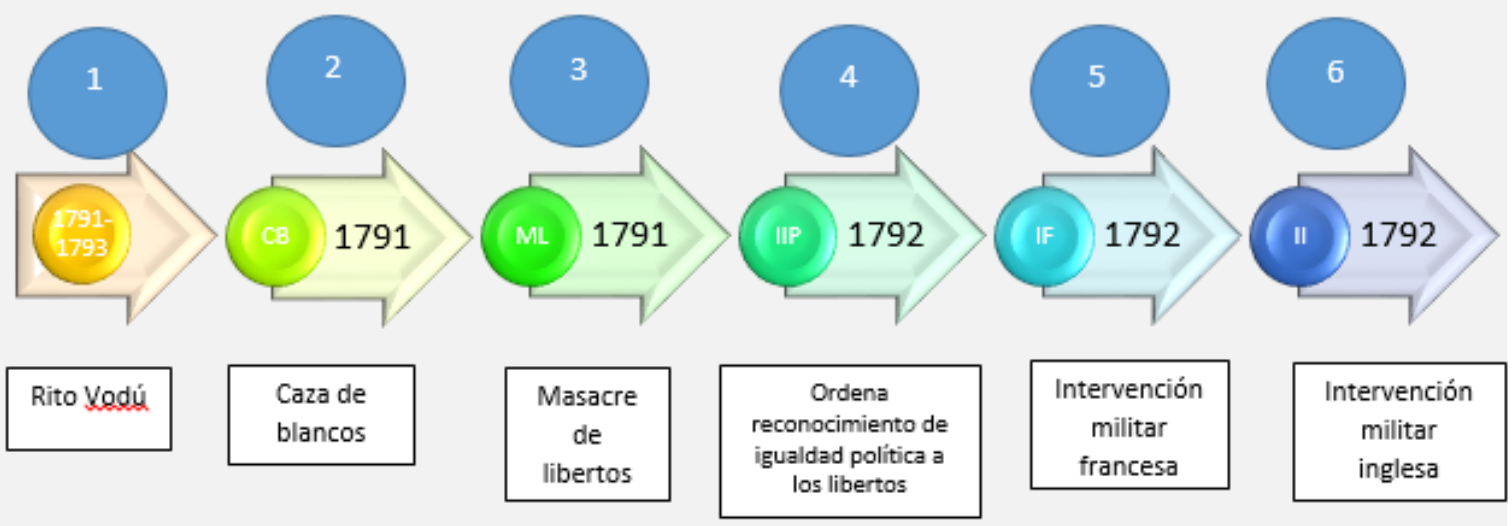

Imagen 1: Línea de tiempo. Elaboración propia.

En 1791 un jamaicano de nombre Boukman realiza un ritual vudú en el que invita a los esclavos a rebelarse ante tanta injusticia. Los explotaban todos los días en las plantaciones sin descanso ni día libre, y el que no pudiera ejercer el trabajo que le correspondía moría a latigazos frente a todos. Los negros esclavos, buscando una solución, proponen una persecución de los blancos que solo termina en desgracia, pues si bien es cierto para la época los esclavos eran el doble de los colonizadores en población, estos últimos tenían armas y conocimientos militares, de modo que terminaron masacrándolos.

\section{(c) (i)(2)}

La Revista Estudios es editada por la Universidad de Costa Rica y se distribuye bajo una Licencia Creative Commons Atribución-NoComercial-CompartirIgual 3.0 Costa Rica. Para más información envíe un mensaje a revistaestudios.eeg@ucr.ac.cr. 
Especial: Profesores de Estudios Generales Investigan

Debido a las continuas sublevaciones es que el gobierno francés decide enviar a 25000 soldados para controlar a 50000 esclavos que ponían en riesgo su economía anclada en la esclavitud, y que para la época era una de las más rentables que tenía entre sus colonias. Debido a lo anterior es que Toussaint Louverture enfrenta a las tropas francesas con ayuda de soldados estadounidenses, venciendo a las primeras. Una vez expulsados los franceses de la isla, no tardaron los ingleses en intentar una nueva intervención para apoderarse de esos territorios tan deseados. Sin embargo, ese intento de los británicos fue fallido.

Los haitianos no podían más y Toussaint Louverture estaba entre los dos mundos, hijo de esclavos, pero ahora liberto que se convirtió en terrateniente no solo de la hacienda en la que nació, sino también de otra que luego le pertenecería; es decir, él también reproducía la esclavitud. Sabía leer, escribir, tenía el poder de mandar a sus iguales. Estas experiencias de vida lo hicieron reflexionar mucho, así como las noticias que recibía de Europa respecto a la Revolución francesa; esos dos elementos le permitieron definir con más claridad las decisiones que debía tomar. De modo que el 22 de agosto de 1971 él encabeza la primera rebelión esclava negra en Santo Domingo, donde los habitantes estaban cansados de tantas injusticias, pero no habían logrado encontrar un líder como Louverture: negro, libre, líder y con un amplio conocimiento militar.

Este haitiano supo combatir a españoles, ingleses y franceses en las diferentes afrentas por la independencia. Sin embargo, lo que más motivaba los pensamientos de Louverture eran dos buenas nuevas del Viejo Mundo: en primer lugar, la Revolución francesa, dónde la monarquía es derrocada, se le corta la cabeza al rey y finalmente el pueblo es libre. Frente a eso, el gobernador se

\section{(c) (i) (2)}

La Revista Estudios es editada por la Universidad de Costa Rica y se distribuye bajo una Licencia Creative Commons Atribución-NoComercial-CompartirIgual 3.0 Costa Rica. Para más información envíe un mensaje a 


\section{Especial: Profesores de Estudios Generales Investigan}

cuestionaba: ¿Por qué, si ellos le cortan la cabeza al rey francés, nosotros debemos seguir obedeciéndole?

En segundo lugar, la Declaración de los Derechos del Hombre y del Ciudadano empieza a alentar el deseo del gobernador de que todos dejen de ser esclavos y sean ciudadanos. Las informaciones se las proveían franceses recién llegados a la isla con los cuales discutía: ¿Por qué si los franceses pueden ser libres nosotros los haitianos no? ¿No somos acaso seres humanos merecedores de los mismos derechos? Estas y otras ideas invadían la mente del libertador negro, deseoso de hacer conocer a su pueblo las mieles de la libertad y la igualdad contenidas en esa declaración que en apariencia aplicaba solo para los franceses.

Este documento también puso en tela de juicio una gran discusión de la modernidad en lo atinente a ¿qué significa ser ciudadano?, ¿qué derechos otorga el ser ciudadano? Todos estos pensamientos filosóficos dignos de discusión y reconocimiento referenciaban las mayores preocupaciones del libertador en torno a la realidad de su pueblo, la libertad y la independencia.

\section{Simón Bolívar y la Gran Colombia}

La Gran Colombia fue el sueño de Simón José Antonio de la Santísima Trinidad Bolívar Palacios Ponte y Blanco, más conocido como Simón Bolívar. Nacido en 1783 en Caracas e hijo de criollos, deseaba liberarse de la Corona española y crear la Gran Colombia.

La Gran Colombia no solo sería un espacio independiente, sino también con su propia administración política, sin intervención de los españoles; los cuales, para 1808, estaban doblegándose ante la invasión de Napoleón Bonaparte, hecho que favoreció el surgimiento de ideas independentistas ante una monarquía

La Revista Estudios es editada por la Universidad de Costa Rica y se distribuye bajo una Licencia Creative Commons Atribución-NoComercial-CompartirIgual 3.0 Costa Rica. Para más información envíe un mensaje a revistaestudios.eeg@ucr.ac.cr. 
española que se debilitaba políticamente y geográficamente. Otros factores que se sumaron fueron:

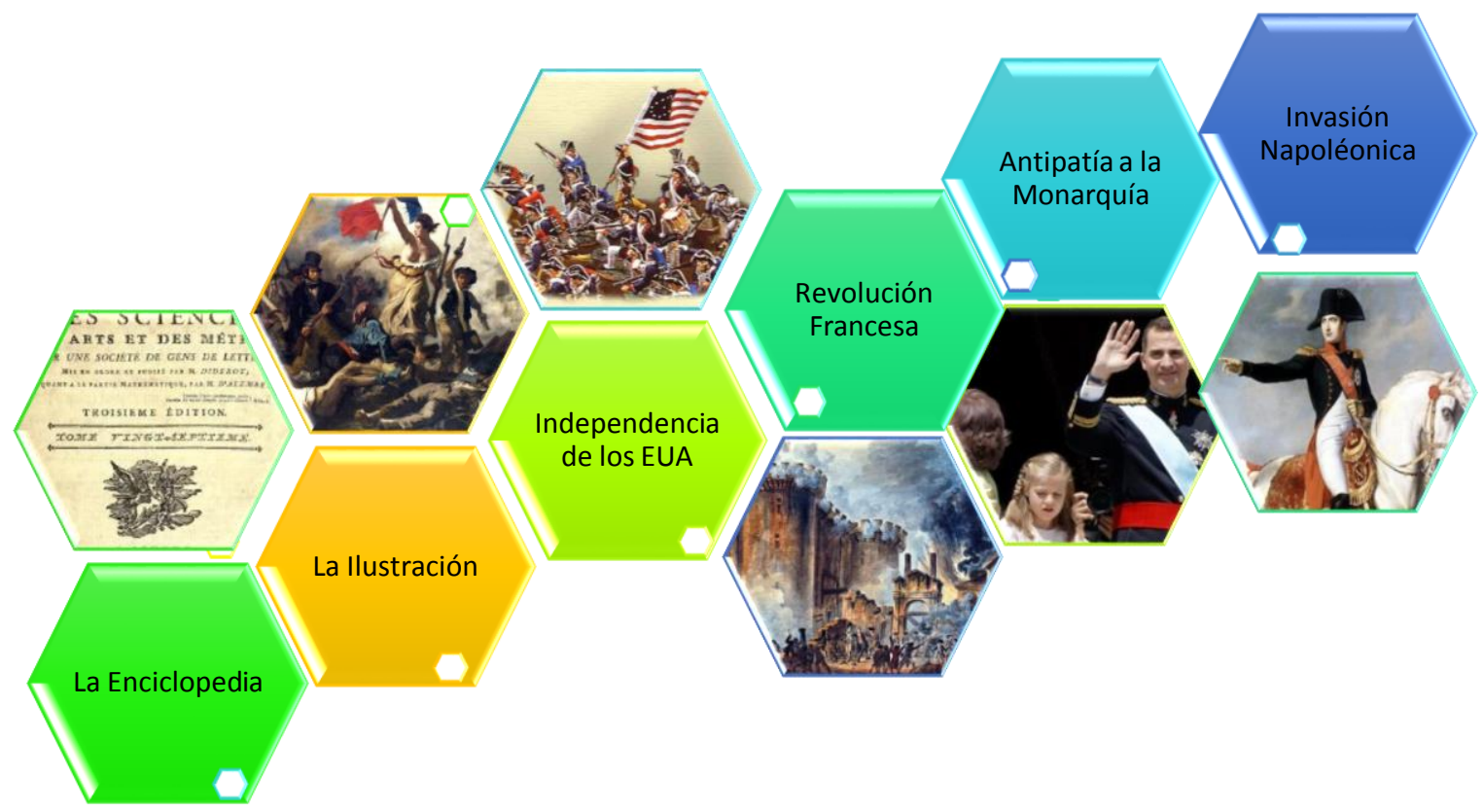

Imagen 2: Factores del contexto europeo y latinoamericano. Elaboración propia.

Aunado a lo anterior, Venezuela también es permeada por las ideas de la Revolución francesa de 1790, sobre todo en lo referente a la libertad y la igualdad.

Simón Bolívar es uno de los primeros militares en América Latina que tiene acceso a las ideas de Jean Jacques Rousseau, pensador francés que pone en duda la tenencia de la propiedad, la igualdad entre los hombres, las formas de gobierno más adecuadas a cada territorio, etc.; ideas que calaron desde la formación educativa con su maestro Simón Rodríguez, gran estudioso de Rousseau.

\section{(๑) $\odot \odot$}

La Revista Estudios es editada por la Universidad de Costa Rica y se distribuye bajo una Licencia Creative Commons Atribución-NoComercial-CompartirIgual 3.0 Costa Rica. Para más información envíe un mensaje a revistaestudios.eeg@ucr.ac.cr. 


\section{Especial: Profesores de Estudios Generales Investigan}

En distintos tiempos, pero con influencias ideológicas similares, el Libertador, como era más conocido Bolívar, compartía el mismo sueño que Toussant Louverture: la independencia, así como vivir los ideales revolucionarios franceses de libertad, igualdad y fraternidad en Venezuela, una tierra que pertenecía al virreinato de Nueva Granada, en donde los criollos explotaban a los esclavos en las plantaciones de cacao, añil, tabaco y en la extracción de minerales, entre otros. El mercado más grande de esclavos se ubicaba en Cartagena de Indias (actual Colombia), su comercio, el más inhumano de todos, más que con productos era con personas.

Sin embargo, Bolívar debía enfrentar dos instituciones que solo vinieron a reforzar el orden colonial administrativo y de esclavitud: la Iglesia y el cabildo.

La iglesia utilizaba las prédicas para recordarle al pueblo que Dios le dio poder a España para mandar sobre América. Además, instigaba en los pobladores el miedo al pecado predicando en las homilías que la insurrección era un pecado contra el rey y contra Dios.

El cabildo acentúa el orden colonial mediante dos medidas. Primero estableció un orden administrativo, político y económico al que solo podían acceder a puestos políticos de mando criollos y españoles. Segundo, reforzó la división de clases sociales entre quienes eran ciudadanos y quienes no (esclavos, mulatos, zambos, etc.). Aunado a lo anterior, lidiaba con un pueblo analfabeto, pero sediento de libertad.

Frente a esto, Simón Bolívar se cuestionaba ¿cómo hacer para lograr la independencia? Tomó entonces las siguientes medidas intelectuales, políticas y militares:

1. Realizar campañas en diferentes países para, desde sus conocimientos, ir integrando al pueblo latinoamericano en la lucha independentista e irles

\section{(C) $(\odot \odot \odot$}

La Revista Estudios es editada por la Universidad de Costa Rica y se distribuye bajo una Licencia Creative Commons Atribución-NoComercial-CompartirIgual 3.0 Costa Rica. Para más información envíe un mensaje a 


\section{Especial: Profesores de Estudios Generales Investigan}

explicando la importancia de esa lucha. Una de las primeras acciones la llevó a cabo con la batalla de Cúcuta el 28 de febrero de 1813, en donde logró la liberación de las poblaciones pertenecientes a los siguientes territorios: Guamal, El Banco, Tenerife, Ocaña y Tamalameque. Otro logro significativo se dio gracias a la batalla de Caracas el 6 de agosto de 1813, en donde crea un nuevo sistema de administración de justicia, así como un nuevo sistema fiscal. Logra la nacionalización de los extranjeros que participaron en la batalla por la construcción de la república. Organiza un régimen militar.

2. El Manifiesto de Cartagena: es un escrito en donde enfatiza que las razones por las cuales la Primera República de Venezuela no prosperó eran: las continuas divisiones internas de los pueblos, la falta de unidad de estos últimos para mirarse más allá de las diferencias como latinoamericanos $\mathrm{y}$, por último, el no proyectarse como un pueblo unido para trabajar por un objetivo común: la independencia.

3. El "Discurso de Angostura" pronuncia los lineamientos políticos que Bolívar recomienda para gobernar Venezuela y América una vez que logren la independencia, entre ellas destacan:

a) Las instituciones han de surgir de las preocupaciones y necesidades de cada país.

b) No se deben copiar modelos de tierras europeas que no se ajustan a la realidad de nuestros países latinoamericanos.

c) Es necesario cuatro poderes: ejecutivo, legislativo, judicial y moral. Este último busca, a través de la virtud, combatir la tiranía de las costumbres que impusieron los españoles.

d) Un congreso de carácter hereditario. Los padres prepararan en la función política y cívica a los hijos para que los remplacen.

\section{(C) $(\Theta \odot \odot$}

La Revista Estudios es editada por la Universidad de Costa Rica y se distribuye bajo una Licencia Creative Commons Atribución-NoComercial-CompartirIgual 3.0 Costa Rica. Para más información envíe un mensaje a 


\section{Especial: Profesores de Estudios Generales Investigan}

e) Educar es tan importante como libertar, por eso afirma "Moral y luces son los polos de una república; moral y luces son nuestras primeras necesidades" (Bolívar, 2008a, p.16)

4. Fundación de la Gran Colombia se proclama en el Congreso de Angostura: es la unión de Nueva Granada (actual Colombia, también nombrada como Cundinamarca, que se extendía hasta Panamá) y Venezuela. Sin embargo, también adhieren a Ecuador, pese a la poca representación que tenía por continuar siendo un territorio dominado por españoles.

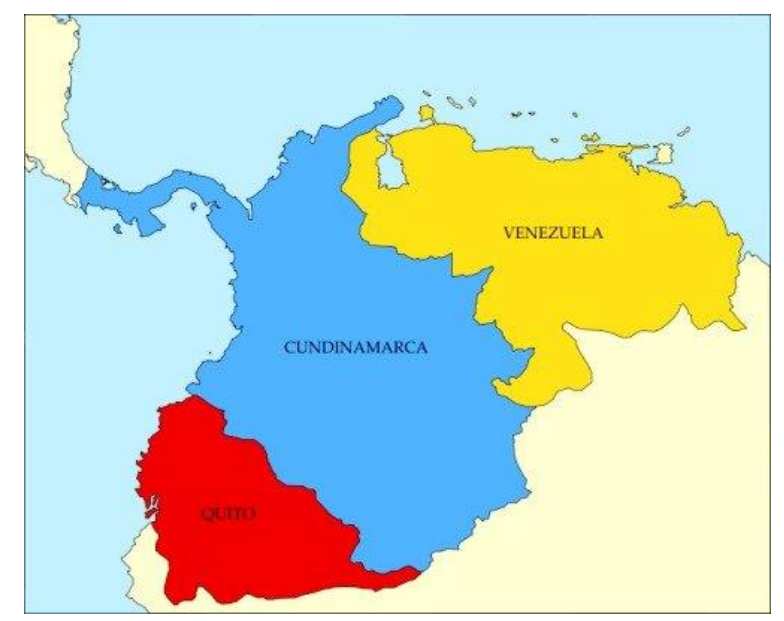

Imagen 3: La Gran Colombia, proclamada el 17 de diciembre de 1819 por Bolívar, comprendía los actuales territorios de Venezuela, Colombia, Ecuador y Panamá.

Haití y Cuba también se intentaron unir a la Gran Colombia. No obstante, esta se comenzó a segregar en 1830.

Las luchas de Bolívar fueron las mayores impulsadoras de la independencia de los países de Suramérica:

- En Venezuela la independencia es proclamada por el pueblo el 19 de abril de 1810. El Acta de Independencia se firma oficialmente el 5 de

\section{(๑) $\Theta \odot$}

La Revista Estudios es editada por la Universidad de Costa Rica y se distribuye bajo una Licencia Creative Commons Atribución-NoComercial-CompartirIgual 3.0 Costa Rica. Para más información envíe un mensaje a 
Especial: Profesores de Estudios Generales Investigan

julio de 1811. Pese a la distancia de meses entre la proclamación y la firma, al presente el pueblo celebra solo la primera fecha.

- En Colombia el Acta de Independencia se firma y se celebra el 20 de julio de 1810. Inició con las luchas de Bolívar y terminó con la batalla de Boyacá.

- En Bolivia la Independencia se conmemora el 9 de agosto de 1825 en honor a la batalla de Junín.

- En Ecuador se festeja el 24 de mayo de 1822. Se alcanzó gracias a la batalla de Pichicha.

Las luchas de Bolívar no fueron en vano, muchos territorios lograron la independencia política. Además, empezaron a dialogar desde diferentes voces las primeras ideas sobre cómo administrar la independencia, el Estado, la libertad, etc.

\section{Morazán entre liberales y conservadores}

José Francisco Morazán Quezada nace el 3 de octubre de 1792 en Honduras. Fue gobernador de la República Federal de Centroamérica en distintos periodos entre 1830 y 1839. Su administración política tuvo continuos enfrentamientos entre los liberales y los conservadores, quienes estaban en proceso de definir cuál sería la mejor forma de gobierno una vez alcanzada la independencia. Los primeros, representados por Morazán, y los segundos, que insistían en mantener formas de gobierno de carácter imperial.

Una segunda preocupación por resolver era permanecer como territorios aislados o formar una república con los mismos, pero cada uno con autonomía de formular sus propias leyes y forma de gobierno. Es así que, en noviembre de 1824, surge la República Federal Centroamericana, conformada por Guatemala, Honduras, El Salvador, Nicaragua y Costa Rica.

\section{(c) (1) (2)}

La Revista Estudios es editada por la Universidad de Costa Rica y se distribuye bajo una Licencia Creative Commons Atribución-NoComercial-CompartirIgual 3.0 Costa Rica. Para más información envíe un mensaje a 


\section{Especial: Profesores de Estudios Generales Investigan}

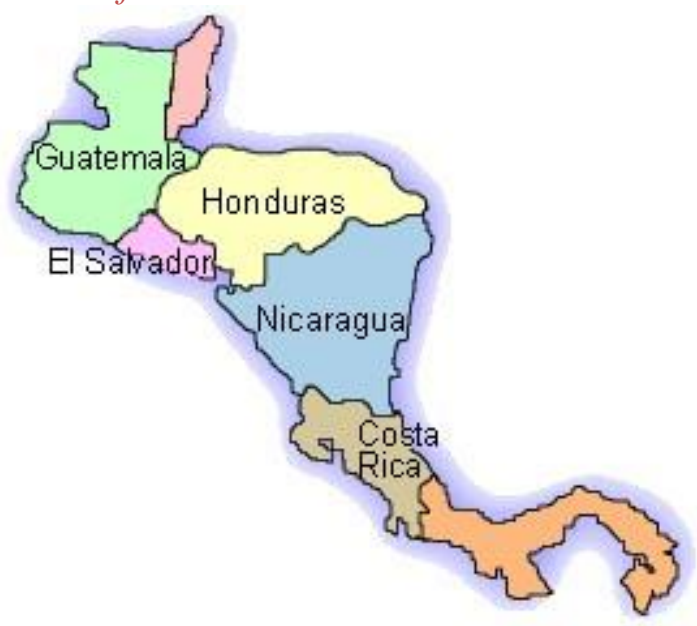

Imagen 4: Mapa de La República Federal Centroamericana.

No obstante, Morazán, en su trayectoria como político e independentista, tuvo que enfrentarse a tres grandes dilemas:

a) Primer dilema: ¿Ser independientes o anexarse a un nuevo imperio?

Posterior a la independencia de España en 1821, llega a Guatemala un escrito de Agustín de Iturbide, en dicho documento se insinúa que unidos Guatemala y el virreinato de México podían formar un gran imperio. Esto desata nuevamente los enfrentamientos a lo interno de Guatemala entre liberales y conservadores de los pueblos de Comayagua y Tegucigalpa, respectivamente. Los primeros pugnaban, sin duda alguna, por la independencia y la construcción de un gobierno propio, y los segundos por la anexión a un imperio poderoso que los respalde, como fuera el español. Unos querían la libertad y otros integrarse a un nuevo imperio para repetir la historia de dominación.

Frente a esto surge la primera actuación militar de Francisco Morazán, quien se enlistó como voluntario en el Ejército de Tegucigalpa para combatir las afrentas de José Tinoco Contreras, gobernador de Comayagua, el cual pugnaba por unirse al imperio mexicano y veía en este la prosperidad. Sin embargo, Morazán no solo era un buen estratega militar, sino que también era un hombre

\section{(c) (i) (2) (2)}

La Revista Estudios es editada por la Universidad de Costa Rica y se distribuye bajo una Licencia Creative Commons Atribución-NoComercial-CompartirIgual 3.0 Costa Rica. Para más información envíe un mensaje a 


\section{Especial: Profesores de Estudios Generales Investigan}

fiel a sus convicciones, se oponía completamente a las intenciones de Contreras, él soñaba una patria independiente de imperialismos y monarquías, como lo hizo Francia con la Revolución francesa; no obstante, este político hondureño no pudo impedir que Guatemala se anexara al Imperio de Iturbide. Sin embargo, está anexión fallida no duró más de siete meses, pues el 1 de julio de 1823 las Provincias Unidas de Centroamérica -primer antecedente de La República Federal Centroamericana- reconocen su independencia definitiva.

Para ese entonces, la República Federal Centroamericana contaba con su propia bandera, escudo, himno y moneda.

b) Segundo dilema: Siendo independientes, ¿cómo organizar el gobierno?

La República Federal Centroamericana inicia un nuevo debate entre:

\begin{tabular}{|c|c|c|}
\hline Tema & Liberales & Conservadores \\
\hline $\begin{array}{l}\text { Forma de } \\
\text { gobierno }\end{array}$ & $\begin{array}{l}\text { Federal, siguiendo el actuar de la } \\
\text { independencia de los Estados } \\
\text { Unidos (1787) y la Constitución } \\
\text { Española de Cádiz (1812) }\end{array}$ & $\begin{array}{l}\text { Centralista, siguiendo el ejemplo de } \\
\text { España, que tenía un centro de mando } \\
\text { único o figura política de capital. }\end{array}$ \\
\hline Leyes & $\begin{array}{l}\text { Cada estado puede gestar y } \\
\text { administrar sus propias leyes. }\end{array}$ & $\begin{array}{l}\text { Se acogen las leyes que imponga el centro } \\
\text { de mando y se aplican de igual modo para } \\
\text { todos los territorios. }\end{array}$ \\
\hline Economía & $\begin{array}{l}\text { Generar nuevas formas de } \\
\text { comercio y con nuevos socios. }\end{array}$ & $\begin{array}{l}\text { Fortalecer la agricultura de cultivos } \\
\text { tradicionales. }\end{array}$ \\
\hline
\end{tabular}

Imagen 5: Elaboración propia.

\section{(2) $(\mathbb{Q} \Theta$}

La Revista Estudios es editada por la Universidad de Costa Rica y se distribuye bajo una Licencia Creative Commons Atribución-NoComercial-CompartirIgual 3.0 Costa Rica. Para más información envíe un mensaje a revistaestudios.eeg@ucr.ac.cr. 


\section{Especial: Profesores de Estudios Generales Investigan}

En este debate se impusieron los conservadores y se elige como primer presidente de la República Federal Centroamericana a Manuel José Arce, quien disuelve el Congreso, formado en gran medida por liberales. Este hecho desató enfrentamientos que terminarían en un golpe de Estado en 1827. De ahí que Morazán tuviera que fungir en determinado momento como jefe provisional del Estado y a su vez tuviera que encabezar la batalla de la Trinidad, en la que recupera el Estado hondureño y propugna la paz. El caminar de Francisco Morazán fue difícil, todavía hacia el final de sus días mantenía continuamente afrentas con quienes se oponían a la independencia.

c) Tercer dilema: ¿Entre el servilismo y la libertad?

Hacia finales de sus días, Morazán hace un recuento de algunos de sus logros, entre ellos:

- Presidente provisional de Honduras.

- Presidente en dos periodos de la República Federal Centroamericana 18301834 y $1835-1839$.

- Jefe de Estado de El Salvador.

- Jefe Supremo de Costa Rica.

Pero en su exilió en Perú por decisión propia, Morazán (1830) redacta su "Manifiesto de David", en alusión a la Ciudad de David en Panamá, cuyo territorio, por ese entonces, pertenecía a Colombia. En este escrito reprocha a los opositores de la independencia.

Hombres que habéis abusado de los derechos más sagrados del pueblo por un sórdido y mezquino interés. Con vosotros hablo, enemigos de la independencia y de la libertad. Si vuestros hechos, para procuraros una patria, pueden sufrir un paralelo con los de aquellos centroamericanos que perseguís o habéis expatriado, yo a su nombre os provoco a presentarlos.

\section{(@) $\odot \otimes \odot$}

La Revista Estudios es editada por la Universidad de Costa Rica y se distribuye bajo una Licencia Creative Commons Atribución-NoComercial-CompartirIgual 3.0 Costa Rica. Para más información envíe un mensaje a revistaestudios.eeg@ucr.ac.cr. 
Especial: Profesores de Estudios Generales Investigan

Ese mismo pueblo que habéis humillado, insultado, envilecido y traicionado tantas veces, que os hace hoy los árbitros de sus destinos y nos proscribe por vuestros consejos, ese pueblo será nuestro juez. (párr.1)

El texto anterior inicia con una de las frases más célebres de Monstesquieu. Para comprender mejor esto último es necesario tener presente algunas de las influencias más representativas de la educación de Francisco Morazán:

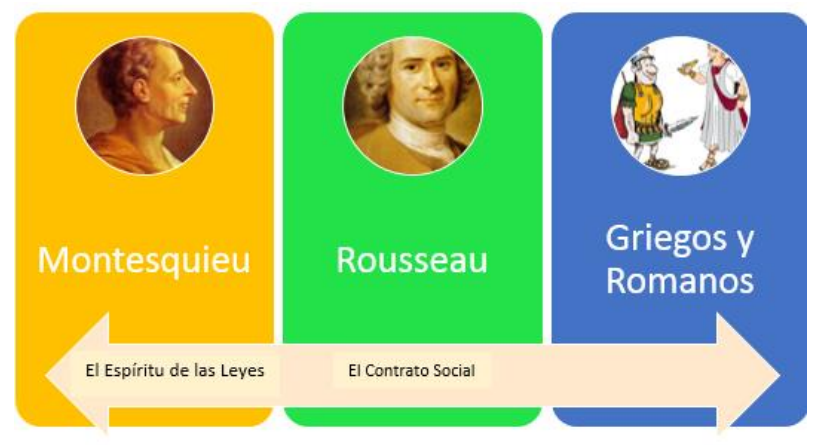

Imagen 6: Elaboración propia.

El Espíritu de las Leyes y El Contrato Social coinciden en un elemento fundamental del buen gobernar: un pueblo que quiera ser independiente debe gestar sus leyes de acuerdo con sus necesidades, intereses y costumbres; una entre muchas ideas sobre administración política que compartía Morazán con estos pensadores. Simón Bolívar tampoco era ajeno a compartir estos aspectos cuando reflexionaba sobre la independencia y a su vez la edificación de la Gran Colombia. No hay conocimiento de que Louverture hubiera leído alguno de esos textos, pero sí de que compartía dos principios políticos expuestos por Rousseau, pregonados en la llustración y replicados en la Revolución francesa: libertad e igualdad para los hombres.

\section{(C) $(\Theta \odot \odot$}

La Revista Estudios es editada por la Universidad de Costa Rica y se distribuye bajo una Licencia Creative Commons Atribución-NoComercial-CompartirIgual 3.0 Costa Rica. Para más información envíe un mensaje a 


\section{Reflexiones finales}

Especial: Profesores de Estudios Generales Investigan

Es inevitable para pueblos subyugados históricamente pensar en independizarse, en alanzar la libertad. Pero, una vez lograda surgen más preguntas: ¿cómo se administra esa libertad?, ¿qué se hace con esa libertad?, ¿todos tienen la misma libertad?, ¿o la libertad es más un sueño que una realidad?

La independencia es también una pregunta por la libertad, pero una libertad con incertidumbre, con duda, con miedo. En la conciencia del latinoamericano la independencia no es innata, es un nuevo proceso fisiológico que aprender para el cuerpo político, una nueva función como humanidad que se reconoce libre.

El camino a la independencia ha sido siempre hasta el día de hoy empedrado, lleno de avances y retrocesos, de intentos, de fracasos y de éxitos, pero nada es tan difícil hasta que se empieza a hacer, y eso lo sabían nuestros independentistas, que anhelaban una historia diferente para América Latina.

La independencia es un proceso constante por emanciparse. Tanto Louverture desde Haití, como Bolívar desde Colombia y también Morazán desde Honduras tuvieron que enfrentar diversas dificultades para lograr la independencia. Los enfrentamientos por la autonomía de estos territorios van más allá de lo meramente militar, implica también lo ideológico, lo contextual, lo poblacional, lo político y las condicionantes de esos tiempos. Bolívar en sus últimos días concluyó que una tarea quedó pendiente: se logró la independencia política y geográfica de España, sin embargo, falta aún lograr la emancipación de pensamiento.

\section{(c) (i) (2) (2)}

La Revista Estudios es editada por la Universidad de Costa Rica y se distribuye bajo una Licencia Creative Commons Atribución-NoComercial-CompartirIgual 3.0 Costa Rica. Para más información envíe un mensaje a 


\section{Referencias bibliográficas}

Especial: Profesores de Estudios Generales Investigan

Alejandro VI. (2010). Primera Bula Inter Caetera (1493). Recuperado de: https://www.biblioteca.org.ar/libros/158131.pdf

Aristóteles. (2012). Ética a Nicómaco. Buenos Aires, Argentina: Editorial Gradifco.

Bolívar, S. (2008a). Discurso de Angostura. Venezuela: Gobierno de Venezuela.

Bolívar, S. (2008b). Manifiesto de Cartagena. Venezuela: Gobierno de Venezuela.

Bolívar, S. (2015). Carta de Jamaica. Venezuela: Ediciones Moon.

Coq, O. (2011). La Révolution française, l'affirmation d'une nouvel univers politique 1789-1804. Recuperado de: https://revolutionfrancaise.net/editions/Cours\%200.\%20Coq\%20RF.net.pdf

De Cauma, J. (2004). Toussaint-Louverture et l'indépendance d'Haïti. Paris, Francia: Editions Karthala-SFHOM.

Donnadiu, J. y Girard, P. (2014). Nouveaux documents sur la vie de Toussaint Louverture. Bulletin de la Société d'Histoire de la Guadeloupe, (166-167). Recuperado de: https://www.erudit.org/fr/revues/bshg/2013-n166-167bshg01267/1023735ar.pdf

Gainot B. (2005a). Esclavage, métissage, liberté. La Révolution française en Guadeloupe. 1789-1802. Annales historiques de la Révolution française, (340). Recuperado de http://journals.openedition.org/ahrf/2023

Gainot B. (2005b). Toussant-Louverture et I'Independence d'Haïti. Annales Historiques de la Révolution française, (340). Recuperado de: https://journals.openedition.org/ahrf/2024

\section{(C) $(00$}

La Revista Estudios es editada por la Universidad de Costa Rica y se distribuye bajo una Licencia Creative Commons Atribución-NoComercial-CompartirIgual 3.0 Costa Rica. Para más información envíe un mensaje a 
Especial: Profesores de Estudios Generales Investigan

Gainot, B., Dorigny, M., Ehrard, J. y Goldstein, A. (juin, 2005). Lumières et esclavage. Annales historiques de la Révolution française. Recuperado de : http://journals.openedition.org/ahrf/13515 ; DOI : 10.4000/ahrf.13515

Morazán, F. (s.f.). Testamento. Presidente de América Central 1792-1842.

Morazán, F. (1870). Memorias del Benemérito General D. Francisco Morazán, antiguo presidente de la República de Centro América escritas por el mismo en David (Nueva Granada) en 1840. Paris, Francia: Imprenta de Rouge Hermanos y Comp.

Morazán, F. (1937). Mensaje del Jefe Provisorio General Morazán a la Asamblea Constituyente de Costa Rica, año de 1824. Revista de los Archivos Nacionales, 2.

Pédagogie du coffret. (2009). De Saint- Domingue à Haïti : Hégémonie française et lutte pour I'Independence. Recuperado de: http://www.cndp.fr/crdpbesancon/fileadmin/CR/Images_CR/editions/toussaint-louverture/De_SaintDomingue_a_Haiti__hegemonie_francaise_et_lutte_pour_I_independance.pdf

Torres, S. (2016, setiembre 19). Declaro que mi amor a Centroamérica muere conmigo. El Heraldo. Recuperado de: https://www.elheraldo.hn/vida/598363-220/declaro-que-mi-amor-acentroamerica-muere-conmigo

Von Grafenstein, J. (mayo-agosto, 2011). Revolución e Independencia de Haití: sus percepciones en las posesiones coloniales vecinas, 1791-1830. Tareas, (138), 33-46. Recuperado de: https://www.redalyc.org/pdf/5350/535055529004.pdf

\section{(C) (๑)}

La Revista Estudios es editada por la Universidad de Costa Rica y se distribuye bajo una Licencia Creative Commons Atribución-NoComercial-CompartirIgual 3.0 Costa Rica. Para más información envíe un mensaje a revistaestudios.eeg@ucr.ac.cr. 